\title{
AUSÊNCIA DE ASSISTÊNCIA À GESTANTE EM SITUAÇÃO DE CÁRCERE PENITENCIÁRIO*
}

\author{
Mayana Camila Barbosa Galvãoํ, Rejane Marie Barbosa Davim²
}

\begin{abstract}
RESUMO: Pesquisa qualitativa teve o objetivo de descrever a experiência vivenciada por mulheres grávidas em sistema penitenciário, entre agosto e setembro de 2011. Empregou-se entrevista semiestruturada a 9 mulheres; utilizou-se a análise de conteúdo da qual emergiu uma categoria central - Vivência de mulheres em situação de cárcere penitenciário durante o periodo gestacional e as três categorias temáticas, sendo apresentado neste recorte: Ausência de assistência à saúde da gestante encarcerada. O estudo revelou que a situação vivida e experienciada pelas gestantes presas no Complexo Penal é delicada, visto que não existe serviço de saúde na instituição, com médicos e enfermeiros, para acompanhar essas mulheres.
\end{abstract}

DESCRITORES: Enfermagem; Gravidez; Prisões; Saúde da mulher.

\section{ABSENCE OF ASSISTANCE FOR THE PREGNANT WOMAN IN PRISON}

ABSTRACT: This qualitative research aimed to describe the experience of pregnant women in the prison system, between August and September 2011. Semi-structured interviews were held with 9 women; content analysis was used, from which a central category emerged - The experience of women in prison during the gestational period and the three thematic categories; this excerpt presents The absence of health care for the imprisoned pregnant woman. The study revealed that the situation lived through and experienced by the pregnant women held in the Prison System is delicate, given that the institution has no health service with doctors or nurses to monitor these women.

DESCRIPTORS: Nursing; Pregnancy; Prisons; Women's health.

\section{AUSENCIA DE ASISTENCIA A LA GESTANTE EN SITUACIÓN DE CÁRCEL PENITENCIARIO}

RESUMEN: Investigación cualitativa cuyo objetivo fue describir la experiencia de mujeres embarazadas en sistema penitenciario, entre agosto y septiembre de 2011. Fue utilizada entrevista semiestructurada con 9 mujeres; también se utilizó el análisis de contenido del donde resultó una categoría central - Experiencia de mujeres en situación de cárcel penitenciario durante el periodo gestacional y tres categorías temáticas, siendo presentada en este estudio: Ausencia de asistencia a la salud de la gestante encarcelada. El estudio reveló que la situación experienciada por las gestantes presas en el Complejo Penal es delicada, ya que no existe servicio de salud en la institución con médicos y enfermeros para acompañar esas mujeres.

DESCRIPTORES: Enfermería; Embarazo; Prisiones; Salud de la mulher.

\footnotetext{
*Recorte de Dissertação de Mestrado apresentada em 2012 ao Programa de Pós-Graduação do Departamento de Enfermagem da Universidade Federal do Rio Grande do Norte - UFRN, sob o título: Vivência de mulheres em situação de cárcere penitenciário durante o período gestacional.

${ }^{1}$ Enfermeira assistencial do Hospital Monsenhor Walfredo Gurgel. Mestre em Enfermagem.

${ }^{2}$ Enfermeira Obstetra. Doutora em Ciências da Saúde. Professora do Curso de Graduação e do Programa de Pós-Graduação em Enfermagem da UFRN. Membro do Grupo de Pesquisa Cuidados de Enfermagem nas Diferentes Fases da Vida.
} 


\section{INTRODUÇÃO}

A Constituição Federal de 1988 e a Lei de Execução Penal de 1984 reconheceram que as pessoas privadas de liberdade têm direito à educação e saúde. Porém só em 2003 os Ministérios da Justiça e da Saúde firmaram parceria para integrar essas ações em um Plano Nacional de Saúde no Sistema Penitenciário (PNSSP). Em 2005, o Ministério da Educação incluiu esse sistema em sua agenda a partir da formulação do Programa Educando para a Liberdade, cujo objetivo é o acesso da população carcerária aos programas nacionais já existentes no âmbito dos referidos ministérios ${ }^{(1)}$.

O PNSSP prevê estruturação de Unidades Básicas de Saúde (UBS) nos estabelecimentos prisionais, institui a necessidade de se definir o fluxo de referência e contrarreferência para as unidades que compõem as redes relativas aos demais níveis de atenção, observando os princípios do Sistema Único de Saúde (SUS) ${ }^{(2)}$.

Entre as linhas prioritárias do PNSSP, estão ações como Atenção Integral à Saúde (AIS), desenvolvidas pelas equipes da Estratégia Saúde da Família (ESF), compostas por psicólogo, assistente social, técnico em enfermagem, médico, enfermeiro, auxiliar de consultório dentário e cirurgião dentista, e atuando nas UBS dentro do Sistema Penitenciário ${ }^{(3)}$.

Entre as ações específicas à saúde da mulher privada de liberdade, preconizadas no PNSSP, estão pré-natal e garantia do acesso das gestantes no atendimento de intercorrências, partos e assistência ao puerpério, controle do câncer cérvico-uterino e de mama, garantindo encaminhamento, tratamento das Doenças Sexualmente Transmissíveis (DST/Aids), assistência à anticoncepção e imunizações ${ }^{(4)}$.

A falta de assistência à saúde é um dos aspectos mais graves que afetam o sistema prisional brasileiro. $\mathrm{O}$ ambiente do estabelecimento penal contribui para o aparecimento de doenças já latentes, ou sua manifestação. Os apenados não têm possibilidade de, por seus próprios meios, procurar atendimento ou medicação diferente do oferecido pelo sistema. No caso do encarceramento feminino, a situação é mais grave, uma vez que não há política específica para o atendimento à mulher presa, em especial quando grávida ${ }^{(5-6)}$.

O descaso com a assistência à saúde de gestantes privadas de liberdade pode ser verificado em um relatório sobre mulheres encarceradas, constatando que, tanto a mãe quanto o feto não têm seus direitos respeitado nos cárceres do Brasil, e só descobrem serem soropositivas e portadoras de outras doenças transmissíveis, na hora do parto tornando-se situação de impacto, e causando profundo conflito psicológico na mãe $e^{(7)}$.

Diante desta problemática e inquietação do tema o qual é escasso na literatura, a motivação para o desenvolvimento desta investigação partiu de situações como as dificuldades do real conhecimento existente dentro dos muros de um presídio feminino que abordem como essas mulheres vivenciaram a gravidez em um ambiente longe de ser o mais ideal para o desenvolvimento de uma gestação normal e saudável. A escolha da temática surgiu de experiências ao participar do grupo de pesquisa Vigilância à Saúde do Programa de Mestrado/Doutorado do Departamento de Enfermagem da Universidade Federal do Rio Grande do Norte (DENF/UFRN) e, trabalhando na área da saúde da mulher, mais especificamente com gestantes e parturientes desde o tempo da graduação, aumentando, assim, o interesse pelo tema e contato com essa população.

Portanto, optou-se por esta pesquisa sobre ausência de assistência à gestante em situação de cárcere penitenciário, objetivando descrever a experiência vivenciada por mulheres grávidas em sistema penitenciário.

\section{MÉTODO}

Pesquisa descritiva qualitativa, desenvolvida no Complexo Penal Feminino Dr. João Chaves (CPFDJC), em Natal, Rio Grande do Norte. Como na maioria dos presídios brasileiros, neste também existem problemas de ordem estruturais, levando a superlotação. No período da coleta de dados, de agosto a setembro de 2011, existiam 135 presas distribuídas em 14 celas, não existindo uma destinada às gestantes, nem berçário para receber os recém-nascidos (RN); gestantes, puérperas e $\mathrm{RN}$ conviviam juntas às demais presas, inclusive com as que tinham doenças infectocontagiosas. A equipe de saúde dentro do complexo é composta apenas por uma assistente social e dois técnicos de enfermagem responsáveis pela administração de medicamentos e cuidados gerais, trabalhando sem supervisão de uma enfermeira.

Nove mulheres participaram da pesquisa. Teve-se como critérios de inclusão: mulheres que vivenciaram a gravidez dentro do CPFDJC, independente de estarem junto com seu filho ou não e encontrar-se em regime fechado, e exclusão: as que vivenciaram a gravidez em outra instituição penitenciária e que ainda estavam grávidas.

O primeiro contato com o local deu-se em abril de 2011 com o vice-diretor da instituição, que encaminhou a chefe do Departamento de Enfermagem da Universidade Federal do Rio Grande do Norte (UFRN) uma decla- 
ração pontuando medidas de segurança adotadas para as pesquisadoras durante as atividades desenvolvidas com as presidiárias na coleta dos dados. A chefe do Departamento enviou um memorando à Divisão de Segurança Patrimonial (DSP) da UFRN, dando ciência das medidas de segurança adotadas pela Direção do CPFDJC. Em resposta ao memorando, o Vice-diretor do DSP/UFRN entendeu que as medidas arroladas eram suficientes para o fim a que se propunha, dando parecer favorável.

Após autorização da DSP/UFRN, fez-se um novo contato com a direção da instituição, confirmando as atividades que seriam desenvolvidas com as participantes da pesquisa conforme calendário, que estavam previstos quatro encontros com as mulheres aos sábados do mês de maio de 2011 das 9 às $10 \mathrm{~h} 30 \mathrm{~min}$, integrando estratégia de aproximação com as mesmas e tinham como objetivo um processo educativo com as presidiárias.

$\mathrm{O}$ primeiro encontro objetivou o acolhimento às presidiárias que vivenciaram a gravidez no Complexo. No segundo, o tema abordado foi sobre os cuidados com o RN e com a criança. No terceiro, falou-se sobre os direitos das crianças dentro de um presídio com a presença de uma advogada para expor esses assuntos e no último encontro discutiu-se sobre as DSTs e os principais métodos anticoncepcionais.

Em virtude ao cumprimento da Resolução 196/96 do Conselho Nacional de Saúde ${ }^{(8)}$ encaminhou-se ao Secretário de Estado da Justiça e da Cidadania (SEJUC) e à Direção da Instituição Penal uma carta solicitando autorização para a pesquisa no estabelecimento. Após anuência do Secretário e da instituição devidamente preenchida, a pesquisa foi encaminhada ao Comitê de Ética em Pesquisa da UFRN sendo a mesma aprovada sem pendências, tendo Protocolo $\mathrm{n}$. 253/2011 e CAAE 0109.0.051.000-11.

Como instrumento, utilizou-se um roteiro de entrevista semiestruturada contendo questões abertas e fechadas, subdividido em três partes: a primeira e a segunda constituídas de variáveis sociodemográficas e obstétricas e a terceira com uma questão norteadora sobre a vivência das mulheres quando estavam grávidas em situação de cárcere ${ }^{(9)}$.

Após parecer favorável do CEP/UFRN, firmou-se contato individual com cada participante, explicando a proposta e interesse em trabalhar com as mesmas sobre a importância do estudo. Foram informadas de que, para proteção da identidade real, seriam identificadas por nomes de flores com aquiescência de todas, assinando o Termo de Consentimento Livre e Esclarecido (TCLE) quando concordavam em participar da pesquisa, ficando uma cópia com a entrevistada e outra com a entrevistadora. Não houve fornecimento de benefícios às entrevistadas, nem riscos de discriminação, mantendo-se o direito de recusar, participar ou responder qualquer pergunta.

Inicialmente, as entrevistas gravadas foram transcritas na íntegra. Posteriormente essas foram analisadas de acordo com os pressupostos da técnica de análise temática ${ }^{(10)}$. O tratamento das informações consistiu em três etapas: na pré-análise, as entrevistas já transcritas foram submetidas à leitura geral e flutuante do material que teve como objetivo familiarização com informações oferecidas; na segunda etapa procedeu-se exploração do material, com leitura detalhada e cuidadosa, identificando-se as unidades de registro ou núcleos de sentido. Por último, realizaram-se os agrupamentos dos núcleos de sentido, codificando-os, classificando-os de acordo com as diferenciações, reagrupando-os conforme características afins ${ }^{(10)}$.

Em seguida foram separados em conjuntos, sendo atribuído um título genérico, conhecendo-se as categorias temáticas originadas; neste artigo optou-se por apresentar a categoria Ausência de assistência à saúde da gestante grávida, e as duas subcategorias: Não acompanhamento do pré-natal e Falta de estrutura do sistema penitenciário para atender as especificidades da gestante.

\section{RESULTADOS}

\section{Caracterizando as participantes da pesquisa}

A faixa etária estava entre 19 a 25 anos, a maioria solteira $(66,7 \%)$ e baixo nível de escolaridade; $66,7 \%$ não haviam concluído o ensino fundamental e 33,7\%, o ensino médio. Ocupação de balconistas, manicures, domésticas, passadeiras de roupa, comércio livre e artistas plásticas. Duas informaram não terem ocupação fixa e com baixa remuneração, tendo em vista a renda familiar; 55,5\% tinham renda de um salário mínimo e $33,3 \%$ não possuíam renda. A média de gestações foi de três e $33,3 \%$ vivenciavam a gravidez pela primeira vez. A média de filhos vivos foi de dois, e três participantes $(33,3 \%)$ afirmaram já terem sofrido aborto.

Quando questionadas se tinham engravidado dentro do presídio ou se estavam grávidas quando foram presas, uma afirmou que sim, as demais já estavam grávidas ao serem encarceradas. Na consulta pré-natal durante a gravidez, a maioria $(77,8 \%)$ afirmou que não o fez. Dentre as que participaram da consulta, a média foi de duas consultas. 
A seguir apresenta-se as duas subcategoria que compõem a categoria Ausência de assistência à saúde da gestante encarcerada.

\section{Não acompanhamento do pré-natal}

Ao analisar as falas das participantes nota-se a falta de assistência e acompanhamento ao pré-natal para a maioria das mulheres que vivenciaram a gestação no presídio:

Nem fiz pré-natal para saber como ela tava, prá mim foi muito ruim, bater ultra também eu não bati, nada disso eu fiz [...]. (Copo de Leite)

Não tive acompanhamento médico, tinha problema de pressão alta, ficava tendo dores fortes, inclusive veio até um papel do juiz prá eu sair, prá me levarem prá fazer o pré-natal, só que eles não me levavam, né [...]. (Lilac)

Não fiz pré-natal porque não tem assistência. Eu pedia prá tomar um remédio se tivesse sentindo dor, aí eles davam, só isso, mas fazer pré-natal não, não fiz nenhum exame. (Íris)

[...] vim prá cá e só fiz exames na maternidade depois que ganhei ela, e acusou sifilis [...]. Eu só vim descobrir a doença depois que ela nasceu, se eu tivesse feito o pré-natal eu tinha tomado conhecimento antes de ter minha filha. (Cravo)

[...] não fiz nenhum exame, não fiz o pré-natal, fui prá maternidade sem exames, né. E que eu perdi [o filho] aqui dentro. Descobriram lá no hospital que eu tava com muita anemia, tomei cinco bolsas de sangue lá, soro, não estavam encontrando minha veia, eu não tinha sangue, não tinha nada. Quase que morro lá no hospital, deram um choque pra mim retornar de novo, fui prá UTI, passei muito tempo mal mesmo. (Violeta)

Fui fazer o pré-natal com sete meses porque estava difícil de carro [...]. (Anêmona)

Sobre o acompanhamento pré-natal nos serviços da rede do SUS, observou-se:

Foi milhões de dificuldade, prá fazer um exame, eu tinha que ficar pedindo, pedindo, aborrecendo as agentes, aborrecendo todo mundo [...] se eu soubesse que a próxima semana, por exemplo, segunda-feira, eu tivesse uma consulta minha marcada para ir, eu começava a perturbar no início já dessa segunda, entendeu? (Gardênia)

Eu cheguei a bater três ultras pela cadeia mesmo e depois fui fazer o pré-natal, acho que ainda cheguei a ir umas duas vezes [...] Fiz o exame de sangue e descobri que tinha sifilis, ai fiz o tratamento e ela também, quando nasceu. (Anêmona)

[...] o setor médico que tinha era a enfermeira [técnico de enfermagem], que você pede o remédio e só dá paracetamol, nada de ver como é que você tá. Era para ter, né, um sistema médico, não tem [...]. (Copo de Leite)

[...] eu pedia assim prá tomar um remédio se tivesse sentindo dor, ai eles davam, só isso [...]. (Íris)

[...] ai eu só passava para o setor médico daqui para verificar a pressão e tomar o sulfato ferroso [...]. (Violeta)

[...] cheguei grávida aqui com sete meses, ai não sentia mexer muito, ai falei com a assistente social, disse a ela que eu não estava muito bem, pedi para marcar uma consulta. Ela disse que ia marcar, mas não conseguiu, que eu esperasse, porque estava sem vaga, e que ia levar umas grávidas primeiro, e que eu não ia ter agora porque eu estava com sete meses. Ai pronto, fiquei esperando, depois fui falar com ela de novo e ela disse que ia marcar uns exames, só que não marcou. Ai eu peguei e esperei, né, e não pedi mais [...]. (Violeta)

\section{Falta de estrutura do sistema penitenciário para atender as especificidades da gestante}

Além do acompanhamento pré-natal, outros fatores estão relacionados com o desenvolvimento saudável de uma gestação, tais como: ambiente confortável, alimentação, apoio familiar, bom relacionamento interpessoal, entre outros. Nas falas das mulheres deste estudo, verificou-se que o sistema penitenciário não está preparado para receber essa população que requer atenção e cuidados diferenciados e especializados:

[...] eu dormia no chão, num colchão, aí lá era muito imprensado, era eu e outra num colchão, eu não dormia só, com um barrigão, não dormia só. Quando tinha que ir ao banheiro, tinha que ter cuidado que era prá não bater nas outras, que não gostavam quando estavam dormindo [...]. (Lilac) 
A falta de escolta foi a pior dificuldade enfrentada, porque quando precisava nunca tinha, como teve algumas presas ai que já perdeu e tudo o bebê. (Copo de Leite)

[...] estava difícil de carro, não tinha carro para levar, eu sempre pedia às agentes e elas sempre ocupadas, nunca se ligou de me levar. (Anêmona)

[...] sempre quando você pedia prá ir [consultar] nunca tinha carro para levar, a desculpa era o carro que nunca tinha. (Cravo)

No que se refere à alimentação, destacaram-se as seguintes falas:

A alimentação eu não gostava não, a quentinha eu não comia, logo que eu cheguei eu não comia, só comia bolacha, miojo, essas coisas. Eu pensei até que o menino ia nascer com pouco peso, mas nasceu até com uns pesinhos mais. (Íris)

[...] as quentinhas são sempre do mesmo jeito, é horrivel, hoje ainda tá melhor, mas antes era pior, quando as quentinhas chegavam, já estavam azedas. (Copo de Leite)

[...] eu só comia mais bolacha e as quentinhas. Eu me sentia fraca, vivia mais deitada, com minha anemia muito forte, nunca tinha alimentação boa. (Violeta)

[...] graças à minha familia minha alimentação foi boa pelas condições familiares, porque pelas condições do presídio não tinha condições, né, de comer a comida que é oferecida aqui. (Lírio).

A alimentação daqui era péssima [...] o pai do meu filho trazia as compras e minha mãe também. Comia muita cenoura e beterraba cruas, fígado mal passado, então eu aproveitei, né. Quando ele [nutricionista] me deu esse receituário, a diretora me deu até o periodo em que eu estivesse amamentando, foi legalizado, para que eu tivesse todas essas coisas. Então, eu aproveitei, e meu filho não nasceu com anemia. (Gardênia).

\section{DISCUSSÃO}

As falas das entrevistadas são preocupantes tanto para essas mulheres, suas famílias, bem como para a saúde pública. Segundo o MS, o pré-natal tem o ob- jetivo de garantir bom acompanhamento das grávidas com informações e orientações ao desenvolvimento do feto, assegurando nascimento de uma criança saudável e bem-estar materno e neonatal. As vantagens do acompanhamento pré-natal englobam diminuição da morbimortalidade materna e fetal, preparação para maternidade e paternidade, autonomia e vivência segura no processo de nascimento ${ }^{(11-12)}$.

A situação vivenciada, além de causar sérios riscos à saúde do bebê e materna, também pode acarretar impacto psicológico na mãe. Quando Cravo referiu: "se tivesse feito o pré-natal teria tomado conhecimento antes de ter minha filha", mostra que as mulheres conhecem a importância do acompanhamento pré-natal com a finalidade de saber como está a saúde da criança, bem como agir na prevenção e detecção de doenças.

Doenças transmissíveis e não transmissíveis podem ser detectadas na consulta médica e do enfermeiro, solicitando-se exames preconizados pelo MS, bem como o início do tratamento ainda na gestação, a fim de curar ou minimizar riscos das doenças e evitar transmissão para o bebê. Um dos problemas de saúde pública mundial e brasileira é a transmissão vertical da sífilis, visto que, dentre tantas doenças que podem ser transmitidas durante o ciclo gravídico-puerperal, a sífilis em gestantes representou, em 2004, uma das maiores taxas $(1,6 \%)$. Esta transmissão pode ocorrer em qualquer fase gestacional, assim, as ações de diagnóstico e prevenção precisam ser reforçadas durante $o$ pré-natal e parto ${ }^{(13)}$.

Os fatores agravantes para a transmissão vertical da sífilis, segundo o MS, podem ser citados como início tardio do pré-natal; uso de esquema terapêutico não recomendado; apenas uma sorologia, tendo em vista que a rotina é de no mínimo dois testes, um no primeiro trimestre e outro após a vigésima oitava semana de gravidez ${ }^{(13)}$.

A saúde e sobrevivência dos recém nascidos estão diretamente atreladas à assistência médica e aos cuidados de saúde em geral recebida pela mãe antes e durante a gestação, parto e puerpério. Durante todo esse período de cuidados continuados de saúde, os momentos com maiores riscos de morte e de incapacidades, tanto para as mães como para os bebês, são o trabalho de parto, o parto e as primeiras horas pós-parto ${ }^{(14)}$.

O Manual Técnico de Atenção Qualificada e Humanizada no Pré-Natal e Puerpério do Ministério da Saúde ${ }^{(15)}$ estabelece como parâmetro que a grávida tem direito à sua primeira consulta no pré-natal até 120 dias da gestação, com um número mínimo de seis consultas, uma no primei- 
ro trimestre, duas no segundo e três no terceiro trimestre.

Observou-se, neste estudo, que a assistência pré-natal, quando acontecia, se desenvolveu em unidades de saúde que fazem parte da rede do SUS. Na maioria dos casos a assistência foi iniciada em um período mais avançado da gravidez, devido às dificuldades de viaturas e escolta policial para o deslocamento das gestantes ao atendimento pré-natal.

O PNSSP determina que as ações e os serviços de assistência básica, o que inclui a assistência ao pré-natal, sejam organizadas nas unidades prisionais e realizadas por equipes interdisciplinares. $\mathrm{O}$ Estado do Rio Grande do Norte aderiu ao plano, porém ainda não está habilitado frente às exigências de adequação do espaço físico e número mínimo de profissionais requeridos pela Portaria Interministerial n. 1.777, de 9 de setembro de $2003^{(16)}$.

Os dados encontrados neste estudo mostraram que as reclusas gestantes do CPFDJC não têm seus direitos garantidos, contrariando a legislação brasileira, visto que, na condição de presa, ela restringe apenas o direito de liberdade e suspende os direitos políticos, e não os direitos referentes à saúde. Na realidade, observa-se que o direito à saúde está sendo descumprido devido à assistência deficitária e precária, e, em determinadas vezes, há falta dessa assistência, tornando isto um problema de saúde pública.

As condições de estrutura física precária e superlotação nos presídios brasileiros são uma realidade constante e preocupante para a saúde, em se tratando da gestante. Esse fato torna-se mais inquietante devido aos cuidados especiais e atenção que requeridos. Quando Lilac expõe sua vivência, observa-se o quanto era desconfortante dividir um colchão com outra presa, estando já com a gravidez bastante avançada, interferindo na qualidade do sono e situações que afetavam diretamente seu bem-estar e do feto.

Destaca-se as precárias condições de habitabilidade das penitenciárias brasileiras, situação esta agravada pela deficiência de recursos humanos especializados e espaço físico necessário à saúde da mulher, o que requer reflexão e ação no âmbito da gestão dos complexos prisionais ${ }^{(17)}$.

A literatura aponta que o maior obstáculo ao atendimento médico nos hospitais e postos de saúde pública é a falta de escolta policial. Com a ausência, precariedade e atraso dessa escolta, veículos e recursos para atender às solicitações da administração penitenciária, ocorrências emergenciais e consultas agendadas ficam prejudicadas, já que as mesmas estão a cargo da polícia, a qual alega falta de pessoal ${ }^{(18)}$.

O relatório sobre mulheres encarceradas no Brasil mostra que houve aumento dessa população, porém sem ser acompanhado por melhorias em sua estrutura. As viaturas ou agentes penitenciárias para cumprir qualquer diligência ou realizar o transporte de presas ao pronto-socorro são escassas, ao ponto de que, entre uma consulta de pré-natal ou uma audiência no fórum, a consulta pré-natal não terá preferência ${ }^{(7)}$.

Durante o período gestacional a alimentação é fator importante para o desenvolvimento da mãe e feto, sendo previstas alterações na dieta da gestante como parte do protocolo da assistência pré-natal. Uma alimentação adequada tem papel importante no período gestacional, não só com efeitos em curto prazo para o crescimento, composição e funções corporais, mas também em longo prazo, podendo interferir no desenvolvimento das funções neurais, comportamentais e no risco de ocorrência de morbimortalidade ${ }^{(19-20)}$.

Alterações de peso na gravidez podem determinar desenvolvimento de complicações, como ganho de peso insuficiente do feto, relacionado ao maior risco de retardo no crescimento intrauterino e mortalidade perinatal, diabetes gestacional, dificuldades no parto e risco para o feto ${ }^{(21)}$.

No CPFDJC, a alimentação das mulheres grávidas não passava por um processo de diferenciação com relação à nutrição das outras mulheres, fato que pode prejudicar o desenvolvimento fetal em longo prazo. No primeiro trimestre gestacional o embrião vai depender da condição pré-gestacional da mãe, em especial das reservas energéticas quanto ao acúmulo de vitaminas e minerais, tendo em vista, da mesma forma, que os dois períodos posteriores são também essenciais no desenvolvimento e crescimento do feto ${ }^{(22)}$.

Em um estudo desenvolvido no Conjunto Penal Feminino da Bahia constatou-se que, das três mulheres grávidas presas, nenhuma atendia aos critérios indicados para manter a eficiência alimentar na gravidez e uma delas afirmou que durante a gestação a família não possuía condições financeiras de alimentos para complementar a oferecida pelo presídio ${ }^{(23)}$.

A realidade encontrada é preocupante e merece olhar diferenciado por parte dos gestores, uma vez que está havendo aumento da população carcerária feminina, principalmente mulheres jovens, em idade fértil, e que a gravidez torna-se cada vez mais constante. Observa-se, portanto, que, estando a mulher privada do seu direito de liberdade está também comprometido o direito à saúde, interferindo no desenvolvimento de sua gestação. 


\section{CONSIDERAÇÕES FINAIS}

Nesta pesquisa a situação experienciada pela gestante presa é bastante delicada, visto que não existe serviço de saúde na instituição, com médicos e enfermeiros, para acompanhar essas mulheres. $\mathrm{O}$ atendimento, quando ocorre, é por técnicos de enfermagem de forma pontual e isolada e quase inexistência de ações específicas para o atendimento.

Não há acompanhamento sistematizado no período do pré-natal, parto e puerpério comprovado pela fala da maioria das mulheres. A situação agrava-se pela falta de escolta policial, disponibilidade de viatura e dificuldade na marcação de consultas na rede do SUS.

Concorda-se que, embora a temática seja pouco pesquisada, é recorrente na realidade brasileira. Este estudo reconhece suas limitações frente à complexidade do tema, porém possibilitou visualização de gestantes no mundo carcerário. Identificou as principais necessidades em saúde dessa população; detectou presença de obstáculos que impedem o atendimento a essas necessidades. Dessa forma, reconhece-se a relevância desta pesquisa na medida em que poderá estimular e instigar, a partir da produção do conhecimento, reflexões e discussões entre pesquisadores e órgãos governamentais, a fim de se reestruturar e garantir a efetiva implantação de uma política pública destinada às gestantes encarceradas.

\section{REFERÊNCIAS}

1. Cestari MEW, Merighi MAB, Baptista PCP. Sentimentos vivenciados por mulheres infectadas pelo HPV ao saberem do diagnóstico da doença. Cienc. cuid saude. [Internet] 2011;10(3) [acesso em 06 out 2012]. Disponível: http://periodicos.uem.br/ojs/índex.php/ CiencCuidSaude/article/view/10054/pdf .

2. Ministério da Justiça. Secretaria Especial de política para as mulheres. Grupo de trabalho interministerial - Reorganização e reformulação do sistema prisional feminino - Relatório Final. Brasília: Ministério da Justiça; 2008.

3. Ministério da Saúde. (BR). Secretaria de Atenção à Saúde. Departamento de Ações Programáticas Estratégicas. Plano Nacional de Saúde no Sistema Penitenciário. Brasília: Ministério da Saúde; 2004.

4. Ministérios da Saúde e da Justiça. Portaria Interministerial n.1777/GM, de 09 de setembro de 2003. Aprova o Plano Nacional de Saúde no Sistema
Penitenciário e define financiamento. Brasília: Ministério da Saúde; 2003.

5. Viafore D. A gravidez no cárcere brasileiro: uma análise da Penitenciária Feminina Madre Pelletier. Direito \& Justiça. 2005;31(2):91-108.

6. Oliveira HC, Cavalcante CM, Cruz EFC, Santos JSP, Souza PSS. Assistência a saúde à mulher - presa: um direito negado. In: Anais do II Seminário Nacional Gênero e Práticas Culturais: culturas, leituras e representações. [Internet] 2009 [acesso em dez 2011]. João Pessoa Editora Universitária UFPB. Disponível: http://itaporanga.net/genero/gt8/2.pdf .

7. Centro pela Justiça e pelo Direito Internacional CEJIL. Relatório sobre mulheres encarceradas no Brasil. [Internet] 2007 [acesso em 01 nov 2011]. Disponível: http://asbrad.com.br/conte\%C3\%BAdo/ relat $\%$ C3\%B3rio_oea.pdf.

8. Ministério da Saúde (BR). Resolução n. 196/96 do Conselho Nacional de Saúde/MS. Sobre Diretrizes e Normas Regulamentadoras de Pesquisa envolvendo seres humanos. Diário Oficial da União, outubro de 1996. Brasília: Ministério da Saúde; 1996.

9. Minayo MCS. O desafio do conhecimento: Pesquisa qualitativa em saúde. 9a ed. São Paulo: Hucitec; 2006.

10. Bardin L. Análise de conteúdo. Portugal: Edições 70; 2010 .

11. Ministério da Saúde (BR). Secretaria de Atenção à Saúde. Departamento de Ações Programáticas Estratégicas. Área Técnica de Saúde da Mulher. Prénatal e Puerpério: atenção qualificada e humanizada - manual técnico. Brasília: Ministério da Saúde; 2006.

12. Zampieri MFM, Erdmann AL. Cuidado humanizado no pré-natal: um olhar para além das divergências e convergências. Rev. Bras. Saúde Mater. Infant. [Internet]. 2010;10 (3) [acesso em 18 mar 2012]. Disponível: http:// dx.doi.org/10.1590/S1519-38292010000300009

13. Lorenzi DRS, Madi JM. Sífilis Congênita como indicador de assistência pré-natal. RBGO 2001; 23(10):647-52.

14. Pearson L, Larsson M, Fauveau V, Standley J. Assistência durante o parto. In: Lawn J, Kerber K. Organizadores. Oportunidades para os recém-nascidos em África: dados práticos, políticas e apoio programático aos cuidados de saúde a prestar aos recém-nascidos africanos. Cape Town: PMNCH; 2006. p.63-78. 
15. Shimizu HE, Lima MG. As dimensões do cuidado prénatal na consulta de enfermagem. Rev. bras. enferm. 2009;62(3):387-92.

16. Ministério da Justiça. Departamento Penitenciário Nacional. Sistema Integrado de Informações Penitenciárias - InfoPen. Formulário Categoria e Indicadores Preenchidos [Internet] 2010 [acesso em 02 nov 2011]. Disponível: http://portal.mj.gov.br/data/ Pages/

17. Santa Rita RP. Mães e crianças atrás das grades: em questão o princípio da dignidade da pessoa humana [dissertação]. Brasília (DF): Universidade de Brasília, Instituto de Ciência Humanas; 2006.

18. Caixeta MC. Plano Nacional de Saúde no Sistema Penitenciário: análise do processo da sua implementação no Distrito Federal [monografia]. Brasília (DF): Universidade de Brasília; 2006.

19. Ministério da Saúde (BR). Secretaria de Atenção à Saúde. Departamento de Ações Programáticas Estratégicas. Área Técnica de Saúde da Mulher. Prénatal e Puerpério: atenção qualificada e humanizada - manual técnico. Brasília: Ministério da Saúde; 2006.

20. Barros DC. O consumo alimentar de gestantes adolescentes no Município do Rio de Janeiro [dissertação]. Rio de Janeiro (RJ): Escola Nacional de Saúde Pública; 2002.

21. Belarmino GO, Moura ERF, Oliveira NC, Freitas GL. Risco nutricional entre gestantes adolescentes. Acta Paul. Enferm. 2009;22(2);169-75.

22. Vitolo MR. Nutrição: da gestação à adolescência. Rio de Janeiro: Reichmann e Affonso Editores; 2003.

23. Souza JGS. Mães, filhos e cárcere: o nascimento atrás das grades [monografia]. Salvador (BA): Universidade Federal da Bahia; 2009. 